\title{
Product Allocation Problem for an AS/RS with Multiple in-the-Aisle Pick Positions
}

\author{
Faraz Ramtin \& Jennifer A. Pazour \\ Department of Industrial Engineering and Management Systems, \\ University of Central Florida,Orlando, FL, 32816, USA \\ E-mail:faraz.ramtin@ucf.edu; jennifer.pazour@ucf.edu
}

\section{A. Optimal $\boldsymbol{m}$ for $C R$ Policy}

$E\left(W_{m}\right)$ is calculated as equations (A.1) and (A.2) for two cases of $b(0<b<1 / 2$ and $1 / 2 \leq b \leq 1)$. Equations (A.1) and (A.2) are continuous piecewise functions. To find the optimal $m$, we follow this procedure for each range of $b$.

STEP 1) Find $m^{*}$ for each range of $m$ by setting $\frac{d E\left(W_{m}\right)}{d m}=0$, then solve for $m$ and calculate the value of $E\left(W_{m^{*}}\right)$ if the $m^{*}$ is in the given range.

STEP 2) Calculate the value of $E\left(W_{m}\right)$ for the beginning and ending of each range of $m$.

STEP 3) Compare the results from STEP 1 and 2 to find the $m^{*}$.

The results of both ranges of $b(0<b<1 / 2$ and $1 / 2 \leq b \leq 1)$ are shown in Table A1 and A2, respectively. For both cases, for the first and third range of $m$, the calculated $m^{*}$ is not in the range; therefore, we calculate the $E\left(W_{m^{*}}\right)$ only for the second range of $m$, and calculate the boundaries value for $E\left(W_{m}\right)$ for the first and third ranges. Finally, we compare the results obtained in the previous steps. The minimum $E\left(W_{m}\right)$ is equal to $b^{2} / 3+1 / 4$, corresponding to $m^{*}=1 / 2$.

Table A1. Results for calculating $m^{*}$ for $0<b<1 / 2$

\begin{tabular}{|c|c|c|c|c|c|}
\hline Interval & \multicolumn{2}{|c|}{$m^{*}$} & \multicolumn{2}{|c|}{ Boundaries value for $E\left(W_{m}\right)$} & $E\left(W_{m^{*}}\right)$ \\
\hline $0 \leq m<b$ & $\begin{array}{l}m^{*}=\sqrt{2 b}-b \\
\text { (not in range) }\end{array}$ & $\begin{array}{l}m^{*}=-\sqrt{2 b}-b \\
\text { (not in range) }\end{array}$ & $\begin{array}{l}E\left(W_{0}\right) \\
=+\infty\end{array}$ & $\begin{array}{l}E\left(W_{b}\right) \\
=5 b^{2} / 6 \\
+(1-b)^{2} / 2\end{array}$ & - \\
\hline$b \leq m<1-b$ & \multicolumn{2}{|c|}{$m^{*}=1 / 2$} & $\begin{array}{l}E\left(W_{b}\right) \\
=5 b^{2} / 6 \\
+(1-b)^{2} / 2\end{array}$ & $\begin{array}{l}E\left(W_{1-b}\right) \\
=5 b^{2} / 6 \\
+(1-b)^{2} / 2\end{array}$ & $\begin{array}{l}E\left(W_{0.5}\right) \\
=b^{2} / 3+1 / 4\end{array}$ \\
\hline $1-b \leq m<1$ & $\begin{array}{l}m^{*}=1-\sqrt{2 b}+b \\
\text { (not in range) }\end{array}$ & $\begin{array}{l}m^{*}=1+\sqrt{2 b}+b \\
\text { (not in range) }\end{array}$ & $\begin{array}{l}E\left(W_{1-b}\right) \\
=5 b^{2} / 6 \\
+(1-b)^{2} / 2\end{array}$ & $\begin{array}{l}E\left(W_{1}\right) \\
=b^{2} / 6+1 / 2\end{array}$ & - \\
\hline
\end{tabular}


Table A2. Results for calculating $m^{*}$ for $1 / 2 \leq b \leq 1$

\begin{tabular}{|c|c|c|c|c|c|}
\hline Interval & \multicolumn{2}{|c|}{$m^{*}$} & \multicolumn{2}{|c|}{ Boundaries value for $E\left(W_{m}\right)$} & $E\left(W_{m^{*}}\right)$ \\
\hline $0 \leq m<1-b$ & $\begin{array}{l}m^{*}=\sqrt{2 b}-b \\
\text { (not in range) }\end{array}$ & $\begin{array}{l}m^{*}=-\sqrt{2 b}-b \\
\text { (not in range) }\end{array}$ & $\begin{array}{l}E\left(W_{0}\right) \\
=+\infty\end{array}$ & $\begin{array}{l}E\left(W_{1-b}\right) \\
=5 b^{2} / 6 \\
+(1-b)^{2} / 2\end{array}$ & - \\
\hline $1-b \leq m<b$ & $m^{*}$ & $1 / 2$ & $\begin{array}{l}E\left(W_{1-b}\right) \\
=5 b^{2} / 6 \\
+(1-b)^{2} / 2\end{array}$ & $\begin{array}{l}E\left(W_{b}\right) \\
=5 b^{2} / 6 \\
+(1-b)^{2} / 2\end{array}$ & $\begin{array}{l}E\left(W_{0.5}\right) \\
=b^{2} / 3+1 / 4\end{array}$ \\
\hline$b \leq m<1$ & $\begin{array}{l}m^{*}=1-\sqrt{2 b}+b \\
\text { (not in range) }\end{array}$ & $\begin{array}{l}m^{*}=1+\sqrt{2 b}+b \\
\text { (not in range) }\end{array}$ & $\begin{array}{l}E\left(W_{b}\right) \\
=5 b^{2} / 6 \\
+(1-b)^{2} / 2\end{array}$ & $\begin{array}{l}E\left(W_{1}\right) \\
=b^{2} / 6+1 / 2\end{array}$ & - \\
\hline
\end{tabular}

\section{B. Proof of $D_{O P T}(m, s)$ is a Valid Probability Distribution Function (PDF)}

Any continuous PDF, $f(x)$, must satisfy the two following conditions. $f(x) \geq 0 \forall x \in \mathbb{R}$, and $\int_{-\infty}^{+\infty} f(x) d x=1$ (Mendenhall \& Sincich, 2006). We show that both conditions hold for $D_{O P T}(m, s)$ as follows.

1) $D_{O P T}(m, s) \geq 0$ for $0 \leq m \leq 1$ and $0 \leq s \leq 1$.

2) $\int_{-\infty}^{+\infty} D_{O P T}(m, s) d x=\int_{0}^{0.5} s(1-2 m)^{s-1} d m+\int_{0.5}^{1} s(2 m-1)^{s-1} d m=1 / 2+1 / 2=1$.

\section{References}

Mendenhall, W., \& Sincich, T. (2006). Statistics for Engineering and the Sciences (5 edition). Pearson, Upper Saddle River, NJ. 